\title{
A randomized phase II trial evaluating the addition of low dose, short course sunitinib to docetaxel in advanced solid tumours
}

Yvonne L. E. Ang ${ }^{1}$, Gwo Fuang Ho², Ross A. Soo ${ }^{1,3}$, Raghav Sundar ${ }^{1,4,5}$, Sing Huang Tan ${ }^{6}$, Wei Peng Yong ${ }^{1,3}$, Samuel G. W. Ow W $^{1,5}$, Joline S. J. Lim ${ }^{1,3}$, Wan Qin Chong ${ }^{1}$, Phyu Pyar Soe', Bee Choo Tai', Lingzhi Wang ${ }^{13,5}$, Boon Cher Goh ${ }^{1,3,5}$ and Soo-Chin Lee Le, $^{1,3 *}$ (D)

\begin{abstract}
Background: We previously reported that low-dose, short-course sunitinib prior to neoadjuvant doxorubicincyclophosphamide (AC) normalised tumour vasculature and improved perfusion, but resulted in neutropenia and delayed subsequent cycles in breast cancer patients. This study combined sunitinib with docetaxel, which has an earlier neutrophil nadir than AC.

Methods: Patients with advanced solid cancers were randomized 1:1 to 3-weekly docetaxel $75 \mathrm{mg} / \mathrm{m}^{2}$, with or without sunitinib $12.5 \mathrm{mg}$ daily for 7 days prior to docetaxel, stratified by primary tumour site. Primary endpoints were objective-response (ORR:CR + PR) and clinical-benefit rate (CBR:CR + PR + SD); secondary endpoints were toxicity and progression-free-survival (PFS).
\end{abstract}

Results: We enrolled 68 patients from 2 study sites; 33 received docetaxel-sunitinib and 35 docetaxel alone, with 33 breast, 25 lung and 10 patients with other cancers.

There was no difference in ORR (30.3\% vs 28.6\%, $p=0.432$, odds-ratio [OR] 1.10, 95\% Cl 0.38-3.18); CBR was lower in the docetaxel-sunitinib arm (48.5\% vs $71.4 \%, p=0.027$ OR $0.37,95 \% \mathrm{Cl} 0.14-1.01)$. Median PFS was shorter in the docetaxel-sunitinib arm (2.9 vs 4.9 months, hazard-ratio [HR] 2.00, 95\% Cl 1.15-3.48, $p=0.014$ ) overall, as well as in breast (4.2 vs 5.6 months, $p=0.048$ ) and other cancers ( 2.0 vs 5.3 months, $p=0.009$ ), but not in lung cancers ( 2.9 vs 4.1 months, $p=0.597$ ). Median OS was similar in both arms overall (9.9 vs 10.5 months, HR $0.92,95 \% \mathrm{Cl} 0.51-1.67$, $p=0.789$ ), and in the breast (18.9 vs 25.8 months, $p=0.354$ ), lung (7.0 vs 6.7 months, $p=0.970$ ) and other cancers (4.5 vs 8.8 months, $p=0.449$ ) subgroups.

Grade $3 / 4$ haematological toxicities were lower with docetaxel-sunitinib (18.2\% vs 34.3\%, $p=0.132$ ), attributed to greater discretionary use of prophylactic G-CSF (90.9\% vs $63.0 \%, p=0.024)$. Grade $3 / 4$ non-haematological toxicities were similar ( $12.1 \%$ vs $14.3 \%, p=0.792)$.

(Continued on next page)

\footnotetext{
*Correspondence: csilsc@nus.edu.sg

'Department of Haematology-Oncology, National University Cancer Institute,

National University Health System, Level 7, NUHS Tower Block, 1E Kent Ridge

Road, Singapore 119228, Singapore

${ }^{3}$ Cancer Science Institute, National University of Singapore, Singapore,

Singapore

Full list of author information is available at the end of the article
}

(c) The Author(s). 2020 Open Access This article is licensed under a Creative Commons Attribution 4.0 International License, which permits use, sharing, adaptation, distribution and reproduction in any medium or format, as long as you give appropriate credit to the original author(s) and the source, provide a link to the Creative Commons licence, and indicate if changes were made. The images or other third party material in this article are included in the article's Creative Commons licence, unless indicated otherwise in a credit line to the material. If material is not included in the article's Creative Commons licence and your intended use is not permitted by statutory regulation or exceeds the permitted use, you will need to obtain permission directly from the copyright holder. To view a copy of this licence, visit http://creativecommons.org/licenses/by/4.0/ The Creative Commons Public Domain Dedication waiver (http://creativecommons.org/publicdomain/zero/1.0/) applies to the data made available in this article, unless otherwise stated in a credit line to the data. 
(Continued from previous page)

Conclusions: The addition of sunitinib to docetaxel was well-tolerated but did not improve outcomes. The possible negative impact in metastatic breast cancer patients is contrary to results of adding sunitinib to neoadjuvant AC. These negative results suggest that the intermittent administration of sunitinib in the current dose and schedule with docetaxel in advanced solid tumours, particularly breast cancers, is not beneficial.

Trial registration: The study was registered (NCT01803503) prospectively on clinicaltrials.gov on 4th March 2013.

Keywords: Tumour vasculature, Anti-angiogenic, Short-course sunitinib, Advanced solid tumours, Docetaxel

\section{Background}

Combining the anti-angiogenic monoclonal antibody bevacizumab with chemotherapy has been shown to improve survival outcomes in various cancers $[1,2]$. However, data from Phase III randomized trials evaluating the addition of small molecule anti-angiogenic tyrosine kinase inhibitors (TKIs) like sunitinib and sorafenib to chemotherapy in solid tumours have been largely negative [3-5]. One possible reason is that optimal dosing and scheduling has not yet been determined. Pre-clinical studies have suggested that anti-angiogenic agents could transiently normalize tumour vasculature, but further continuous administration at full dose of these agents results in destruction of tumour vasculature $[6,7]$. This may paradoxically result in reduced delivery of chemotherapy to the tumour $[8,9]$. Intermittent dosing of a small molecule TKI at a lower dose prior to chemotherapy to transiently 'normalize' tumour vasculature may improve drug and oxygen delivery and thus potentiate sensitivity to chemotherapy $[10,11]$.

We previously conducted a Phase Ib followed by randomized Phase II trial of short-course, low-dose sunitinib prior to neoadjuvant doxorubicin-cyclophosphamide (AC) for 4 cycles in breast cancer in an attempt to normalize tumour vasculature. In phase Ib, sunitinib 25 mg daily for 1 week prior to AC resulted in tumor vessel destruction on immunohistochemistry, while a lower dose of $12.5 \mathrm{mg}$ daily normalized tumor vessels. Thus, $12.5 \mathrm{mg}$ sunitinib for 1 week was tested in the phase II randomized trial of $\mathrm{AC}$ with or without pre-treatment with $12.5 \mathrm{mg}$ sunitinib. Low dose sunitinib + AC resulted in immunohistochemical evidence of increased vascular normalization index, DCE-MRI evidence of improved perfusion, higher objective clinical response rates (60.9\% vs $34.8 \%, p=0.08)$, and tumour volume reduction measured on DCE-MRI compared to AC alone. However, the pathological complete response rate at surgery after 4 cycles of $\mathrm{AC}$ was not different with or without sunitinib, which we postulated may have been attributed to increased myelosuppression from sunitinib causing significantly more treatment delays in subsequent AC cycles [12].

We hypothesized that docetaxel, which has an earlier neutrophil nadir at Day 7-10 compared to AC, will result in less overlapping myelosuppression when combined with intermittent dosing sunitinib in breast cancer as well as other solid tumors, and tested this hypothesis in a randomized phase II trial.

\section{Methods \\ Patients}

We enrolled patients who were at least 18 years of age and had a histologic or cytologic diagnosis of carcinoma, with a measurable tumour (defined as a clinically palpable tumour with both diameters $2.0 \mathrm{~cm}$ or greater, or radiologically measurable by RECIST criteria). Patients who had advanced solid tumours that were not amenable to curative treatment and had an estimated life expectancy of at least 12 weeks were included. Other key eligibility criteria included Eastern Cooperative Oncology Group (ECOG) performance status of 0 or 1 , and adequate haematologic, hepatic and renal function. Patients were excluded if they were pregnant or lactating, or had active infections, active bleeding, poorly controlled diabetes mellitus, non-healing wounds, symptomatic brain metastases, systemic connective tissue diseases or second primary malignancies. All patients gave written informed consent.

\section{Study design}

This study was a randomized open-label Phase II trial of intermittent sunitinib in combination with docetaxel involving two study sites- the National University Cancer Institute in Singapore and the University of Malaya Medical Centre in Malaysia. Patients were randomized 1:1 to receive sunitinib and docetaxel or docetaxel alone. Randomization was stratified according to the primary tumour (breast vs lung cancer vs others) to account for the potential impact of tumor type on treatment response. Simple randomization was performed by the selection of sealed envelopes containing the designated study arm. These were kept and allocated by a research administrator who was not involved in patient enrollment or treatment.

Patients in the experimental arm received sunitinib $12.5 \mathrm{mg}$ orally for 7 days prior to docetaxel. Docetaxel was given at $75 \mathrm{mg} / \mathrm{m}^{2}$, once every 3 weeks, up to a maximum of 6 cycles. In the control arm, patients received 
docetaxel alone. The administration of prophylactic colony stimulating factors was at the discretion of the investigators. Standard pre-medications were employed for the first cycle, with modifications in subsequent cycles permitted at investigator's discretion. Dose modifications of docetaxel in response to toxicities were allowed. No dose modifications were allowed for sunitinib. Treatment was discontinued at the point of tumour progression, unacceptable toxicities or withdrawal of patient consent.

The study was registered (NCT01803503) and approved by the institutional review board at each participating centre and was conducted in accordance with the Declaration of Helsinki and Good Clinical Practice guidelines. The study adheres to CONSORT guidelines [13].

\section{Efficacy, safety}

The co-primary endpoints of the study were objective response rate (defined as the proportion of patients who achieved complete or partial response) and clinical benefit rate (proportion of patients who achieved complete response, partial response or stable disease for at least 12 weeks). Secondary endpoints included progressionfree survival, defined as the time from randomization to date of documented disease progression or death from any cause, and safety. If progression or death did not occur, patients were continued on follow-up and censored at the date of last contact, or the date of study closure (27 February 2020), whichever was earlier.

Tumour response was assessed according to the Response Evaluation Criteria in Solid Tumours version 1.1 (RECIST 1.1) [14]. Clinical assessments were performed at baseline (within 2 weeks prior to enrollment), and every 3 weeks, prior to the start of every treatment cycle. Radiologic assessments with CT scan of the thorax and abdomen $(+/-$ pelvis at investigator's discretion) were performed at baseline (within 4 weeks prior to enrollment), and prior to the start of every other treatment cycle. Response assessment was conducted by the investigator. Safety was assessed by documentation of adverse events, patient reporting, physical examination and biochemical and haematologic clinical laboratory tests. Patients were evaluated weekly for toxicity assessments during cycle 1 , and on days 1 and 15 of each subsequent cycle. Adverse events were graded with the use of the Common Terminology Criteria for Adverse Events of the National Cancer Institute version 3 (NCI CTCAE v3). All patients who received at least one dose of study drug were included in the efficacy and safety analysis.

Blood samples for pharmacokinetic sampling were taken at $0 \mathrm{~min}$ (prior to dosing), $30 \mathrm{~min}, 60 \mathrm{~min}, 2 \mathrm{~h}, 5 \mathrm{~h}, 7 \mathrm{~h}$ and $24 \mathrm{~h}$ on Cycle 1 Day 1 for docetaxel. Docetaxel concentrations were analysed using liquid chromatography-tandem mass spectrometry [15].

\section{Statistical analysis}

The estimated objective response rate to docetaxel in advanced solid tumours is approximately $20 \%[16,17]$. We hypothesized that the concomitant administration of intermittent sunitinib with standard docetaxel will increase the objective response rate by 2 -fold to approximately $40 \%$ based on our previous observation that adding low-dose intermittent sunitinib to doxorubicin/ cyclophosphamide chemotherapy almost doubled the objective clinical response rate after cycle 1 chemotherapy from 34.8 to $60.9 \%$ [12]. Based on a power of $80 \%$ and a one-sided test size of $15 \%$, a minimum sample size of 33 evaluable patients per group was required.

The primary endpoints were analyzed in all patients who received the randomized treatment, in an intention to treat analysis assuming a one-sided test, whereas secondary endpoints were evaluated using a two-sided test at the 5\% level of significance. Safety analyses were performed on the basis of treatment received. Response rates between treatment groups were compared using the Mantel-Haenszel method, stratified by primary tumour. Progression-free and overall survival analysis was performed using the Kaplan-Meier method, with differences in survival distributions compared using the stratified log-rank test, stratified by tumour site. A stratified Cox proportional-hazards model was used to estimate hazard ratios and 95\% confidence intervals.

\section{Results}

\section{Patient characteristics}

Between August 2013 and September 2017, 68 patients were enrolled (49 at the National University Cancer Institute, Singapore and 19 at University of Malaya, Malaysia). Trial enrollment was closed in September 2017 as the trial had completed enrollment. Of these, 33 were randomized to the docetaxel-sunitinib arm and 35 to the docetaxel alone arm; 33 patients had breast cancer, 25 patients had lung cancer and 10 patients had other cancers (Fig. 1). The majority of patients were female (64.7\%), Chinese (66.2\%) and had adenocarcinoma (52.9\%). The treatment groups were balanced with respect to baseline demographic and disease characteristics, except that the docetaxel-sunitinib group had a higher proportion of Chinese patients (84.8\%) compared to the docetaxel alone group (48.6\%) (Table 1). Of the patients in the docetaxel-sunitinib group, 33.3\% had received 2 or more previous lines of therapy in the advanced setting, versus $40.0 \%$ of the patients in the docetaxel alone group, and $30.3 \%$ versus $31.4 \%$ respectively had received no previous palliative therapy.

\section{Treatment characteristics}

At the time of analysis, 64 patients had progressed or died, and 48 patients had died. All 68 patients have 


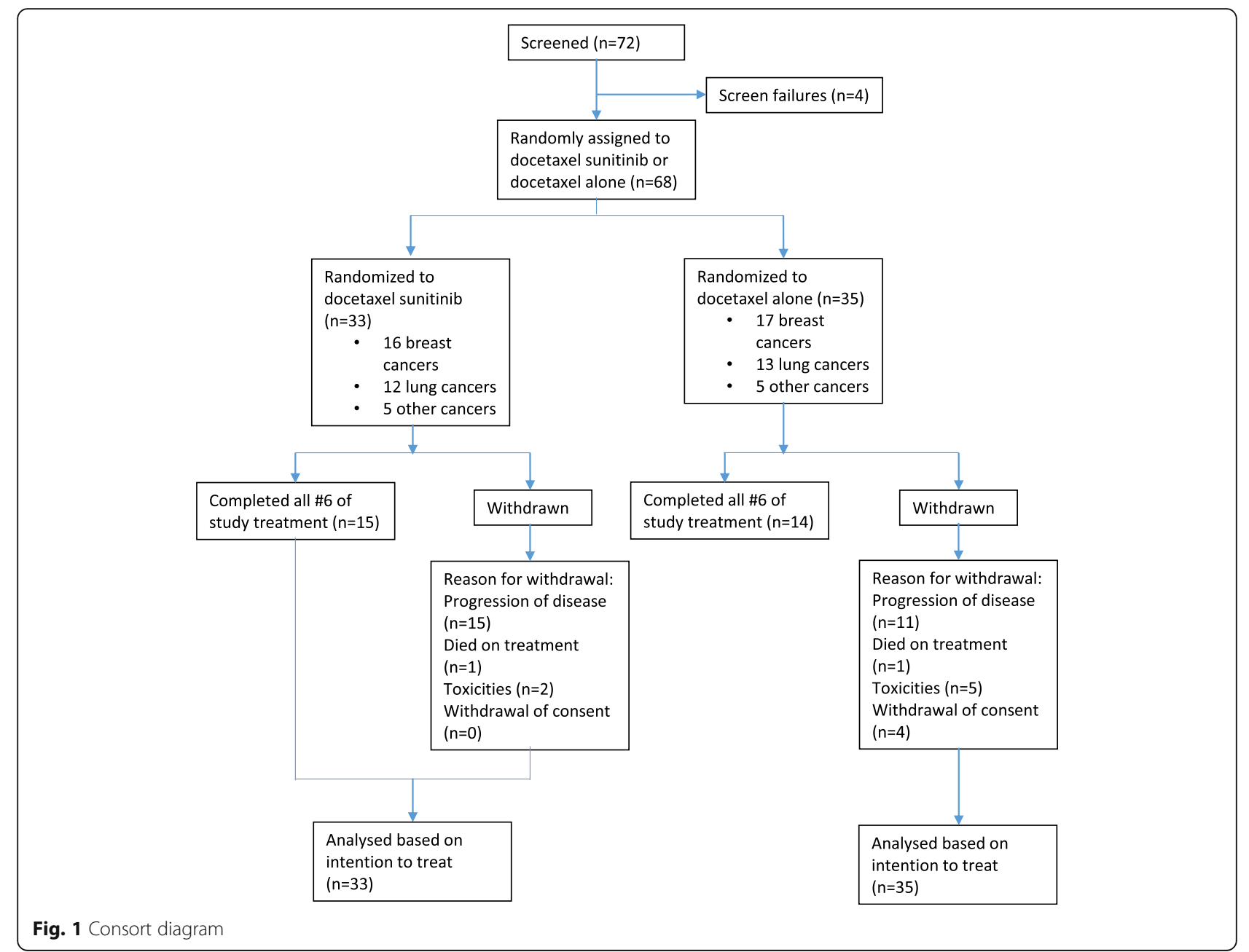

discontinued treatment: 29 patients completed all $6 \mathrm{cy}-$ cles of docetaxel treatment, 26 patients had treatment stopped due to progression of disease, 2 died during treatment, 7 were taken off the study due to toxicities and 4 withdrew from the study for other reasons.

The mean duration of treatment was 12.4 weeks in the docetaxel-sunitinib group and 14.1 weeks in the docetaxel alone group $(p=0.284)$. The mean dose intensity of docetaxel in the docetaxel-sunitinib arm was $23.6 \mathrm{mg} /$ $\mathrm{m}^{2} /$ week, vs $24.5 \mathrm{mg} / \mathrm{m}^{2} /$ week in the docetaxel alone arm $(p=0.303)$. Patients received a median of 4 and 5 cycles of treatment in each group respectively $(p=$ 0.940 ). Dose delays of $\geq 1$ week were seen in 18.2 and $11.4 \%$ of patients in the docetaxel-sunitinib versus docetaxel alone groups $(p=0.432)$. Of the 49 patients in whom use of granulocyte stimulating factor (G-CSF) was recorded, $37 / 49$ (76\%) received G-CSF as prophylaxis (36 as primary prophylaxis, 1 as secondary prophylaxis). Significantly more patients in the docetaxel-sunitinib arm received G-CSF compared to those in the docetaxel alone arm $(90.9 \%$ vs $63.0 \%, p=0.024)$.

\section{Efficacy}

The primary endpoint of objective response rate was similar in both arms, with an ORR of $30.3 \%$ in the docetaxel-sunitinib arm vs $28.6 \%$ in the docetaxel alone arm ( $p=0.432$, OR 1.10, 95\% CI 0.38-3.18). Clinical benefit rates were lower in the docetaxel-sunitinib arm at $48.5 \%$ vs $71.4 \%,(p=0.027$, OR $0.37,95 \%$ CI $0.14-$ 1.01). Subgroup analysis was performed on ORR and CBR in the different tumour types. In breast cancer, the ORR was $43.8 \%$ vs $35.3 \%(p=0.619)$ and the CBR $68.8 \%$ vs $76.5 \%(p=0.619)$; in lung cancer, the ORR was $16.7 \%$ vs $30.8 \%(p=0.409)$ and the CBR $33.3 \%$ vs $53.8 \%(p=$ $0.302)$; in other cancers, the ORR was $20 \%$ vs $0 \%$ ( $p=$ $0.292)$ and the CBR $20 \%$ vs $100 \%(p=0.010)$.

In the secondary endpoint of progression-free survival (PFS), the addition of sunitinib to docetaxel was associated with a shorter PFS when compared with docetaxel alone (2.9 months vs 4.9 months, HR 2.00 , 95\% CI $1.15-$ 3.48, $p=0.014$ ) (Fig. 2). Exploratory subgroup analysis by tumour type showed the difference in PFS remained significant in patients with breast cancer (4.2 months vs 
Table 1 Demographic and Disease Characteristics of the Patients at Baseline

\begin{tabular}{|c|c|c|c|}
\hline Characteristics & Docetaxel-sunitinib $(N=33)$ & Docetaxel alone $(N=35)$ & Overall $(N=68)$ \\
\hline \multicolumn{4}{|l|}{ Gender } \\
\hline Male & $11(33.3 \%)$ & $13(37.1 \%)$ & $24(35.3 \%)$ \\
\hline Female & $22(66.7 \%)$ & $22(62.9 \%)$ & $44(64.7 \%)$ \\
\hline Mean age (range), years & $55.4(34.0-76.0)$ & $57.1(35.7-74.5)$ & $56.3(34.0-76.0)$ \\
\hline \multicolumn{4}{|l|}{ Race } \\
\hline Chinese & $28(84.8 \%)$ & $17(48.6 \%)$ & $44(66.2 \%)$ \\
\hline Indian & $0(0 \%)$ & $3(8.6 \%)$ & $3(4.4 \%)$ \\
\hline Malay & $4(12.1 \%)$ & $11(31.4 \%)$ & $15(22.1 \%)$ \\
\hline Others & $1(3.0 \%)$ & $4(11.4 \%)$ & $5(7.4 \%)$ \\
\hline \multicolumn{4}{|l|}{ Site of primary tumour } \\
\hline Breast & $16(48.5 \%)$ & $17(48.6 \%)$ & $33(48.5 \%)$ \\
\hline Lung & $12(36.4 \%)$ & $13(37.1 \%)$ & $25(36.8 \%)$ \\
\hline Others & $5(15.2 \%)$ & $5(14.3 \%)$ & $10(14.7 \%)$ \\
\hline \multicolumn{4}{|l|}{ `Histology } \\
\hline Adenocarcinoma & $16(48.5 \%)$ & $20(57.1 \%)$ & $36(52.9 \%)$ \\
\hline Squamous carcinoma & $13(39.4 \%)$ & $12(34.3 \%)$ & $25(36.8 \%)$ \\
\hline Others (including poorly differentiated, NOS, lymphoma, small cell) & $4(12.1 \%)$ & $3(8.6 \%)$ & $7(10.3 \%)$ \\
\hline \multicolumn{4}{|l|}{ Lines of prior palliative therapy } \\
\hline 0 & $10(30.3 \%)$ & $11(31.4 \%)$ & $21(30.9 \%)$ \\
\hline 1 & $12(36.4 \%)$ & $10(28.6 \%)$ & $22(32.4 \%)$ \\
\hline 2 & $6(18.2 \%)$ & $8(22.9 \%)$ & $14(20.6 \%)$ \\
\hline 3 & $4(12.1 \%)$ & $2(5.7 \%)$ & $6(8.8 \%)$ \\
\hline 4 & $1(3.0 \%)$ & $2(5.7 \%)$ & $3(4.4 \%)$ \\
\hline$>/=5$ & $0(0 \%)$ & $2(5.7 \%)$ & $2(3.0 \%)$ \\
\hline
\end{tabular}

5.6 months, $p=0.048)$ and other cancers (2.0 months vs 5.3 months, $p=0.009$ ), but was not significant in the lung cancer subgroup (2.9 months vs 4.1 months, $p=$ 0.597). Overall survival (OS) was similar in both groups (9.9 months vs 10.5 months, HR 0.922 , 95\% CI $0.51-$ 1.67, $p=0.789$ ) (Fig. 3). There was also no OS benefit from the addition of sunitinib in any of the tumour subgroups: in breast cancers, OS was 18.9 months vs 25.8 months $(p=0.354)$, in lung cancers, OS was 7.0 months vs 6.7 months $(p=0.970)$ and in other cancers OS was 4.5 months vs 8.8 months $(p=0.449)$.

\section{Adverse events}

The addition of sunitinib to docetaxel was generally well tolerated. The rates of adverse events of all grades was similar in both arms, at $84.8 \%$ in the docetaxel-sunitinib arm versus $91.4 \%$ in the docetaxel alone $\operatorname{arm}(p=0.400)$. Rates of Grade 3/4 non-haematological toxicities were similar in both arms, at $12.1 \%$ versus $14.3 \%(p=0.792)$, but rates of Grade 3/4 haematological toxicities were lower in the docetaxel-sunitinib arm at $18.2 \%$ compared to $34.3 \%$ in the docetaxel alone arm $(p=0.132)$, likely attributed to greater use of prophylactic growth factors in the docetaxel-sunitinib arm. 0 and $5.7 \%$ of patients experienced febrile neutropenia respectively $(p=0.163)$. None of the dose delays were due to neutropenia; reasons for delay included exacerbation of chronic obstructive pulmonary disease, drainage of pleural effusions and herpes zoster. Table 2 shows the rates of serious toxicities and all grade toxicities that occurred in $\geq 5 \%$ patients. As expected, low dose, short course sunitinib was not associated with VEGFR tyrosine kinase inhibitor related adverse events.

\section{Pharmacokinetic analysis}

Of the 68 patients enrolled in the study, 63 had blood samples available for pharmacokinetic analysis (Table 3). Docetaxel area under the curve $\left(\mathrm{AUC}_{0-\infty}\right)$ was numerically higher for patients who received docetaxel-sunitinib vs those with docetaxel alone $\left(6.48 \pm 4.43 \mathrm{~h}^{*} \mu \mathrm{g} / \mathrm{ml}\right.$ vs $\left.4.85 \pm 1.76 \mathrm{~h}^{*} \mathrm{\mu g} / \mathrm{ml}, p=0.053\right)$, although the difference did not reach statistical significance. Docetaxel clearance was not significantly different in the two groups $(24.4 \pm$ 13.2 L/h vs $27.4 \pm 8.7 \mathrm{~L} / \mathrm{h}$ for docetaxel-sunitinib vs docetaxel alone, $p=0.290)$. The predicted volume of 


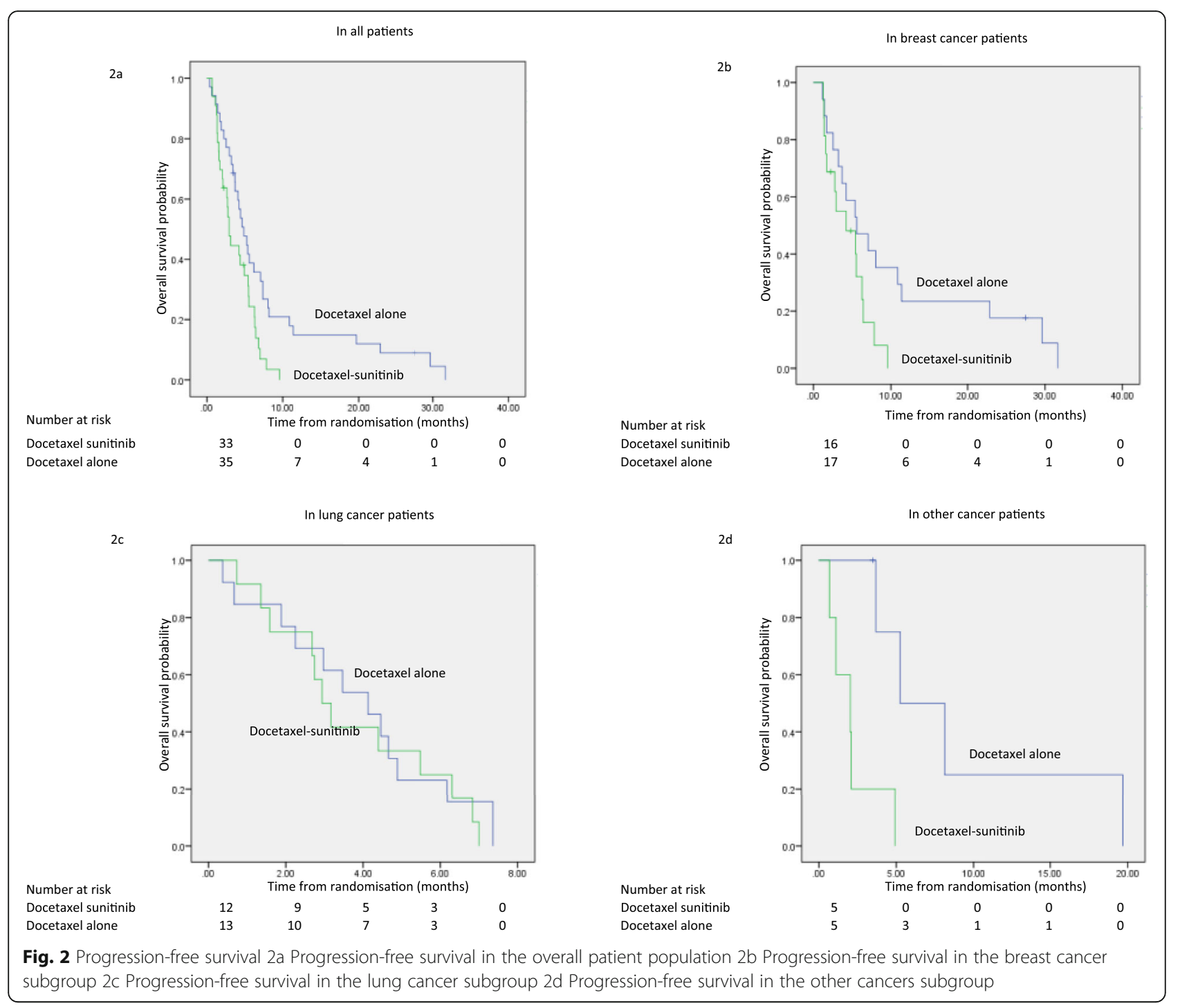

distribution of docetaxel (Vss_pred) was similar in both arms at $193.5 \pm 248.2 \mathrm{~L}$ vs $198.5 \pm 148.6 \mathrm{~L}(p=0.922)$.

We examined whether docetaxel $\mathrm{AUC}_{0-\infty}$ correlated with efficacy outcomes. Using mean $\mathrm{AUC}_{0-\infty}$ as the cutoff to divide the cohort into those with high versus low docetaxel $\mathrm{AUC}_{0-\infty}$, no significant difference in PFS, objective response rate, or clinical benefit rate, was observed between patients with high versus low docetaxel $\mathrm{AUC}_{0-\infty}$ (PFS 4.1 months vs 4.6 months, $p=0.141$; ORR $30.4 \%$ vs $25.0 \%, p=0.640$; CBR $56.5 \%$ vs $62.5 \%, p=0.641$ ).

\section{Discussion}

We have previously shown that administering low-dose, short-course sunitinib at $12.5 \mathrm{mg}$ for 1 week before neoadjuvant doxorubicin-cyclophosphamide (AC) chemotherapy in breast cancer resulted in histological evidence of vascular normalization and DCE-MRI evidence of improved tumour perfusion and greater reduction in tumour volume, possibly due to improved chemotherapy delivery into the cancer. However, this did not translate to improved rates of pathologic complete response after repeated cycles of chemotherapy. We postulated that this could be due to more prolonged neutropenia from AC chemotherapy with addition of sunitinib that led to overall reduced chemotherapy dose intensity [12].

We therefore set out to evaluate the same strategy of low-dose, short-course sunitinib preceding chemotherapy but with docetaxel, which has an earlier neutrophil nadir than $\mathrm{AC}$, with the hypothesis that this combination will be less myelosuppressive. Disappointingly, we observed no improvement in objective response rate, clinical benefit rate, or progression-free survival with the addition of sunitinib. One possible reason is that the normalization of tumour vasculature achieved with 


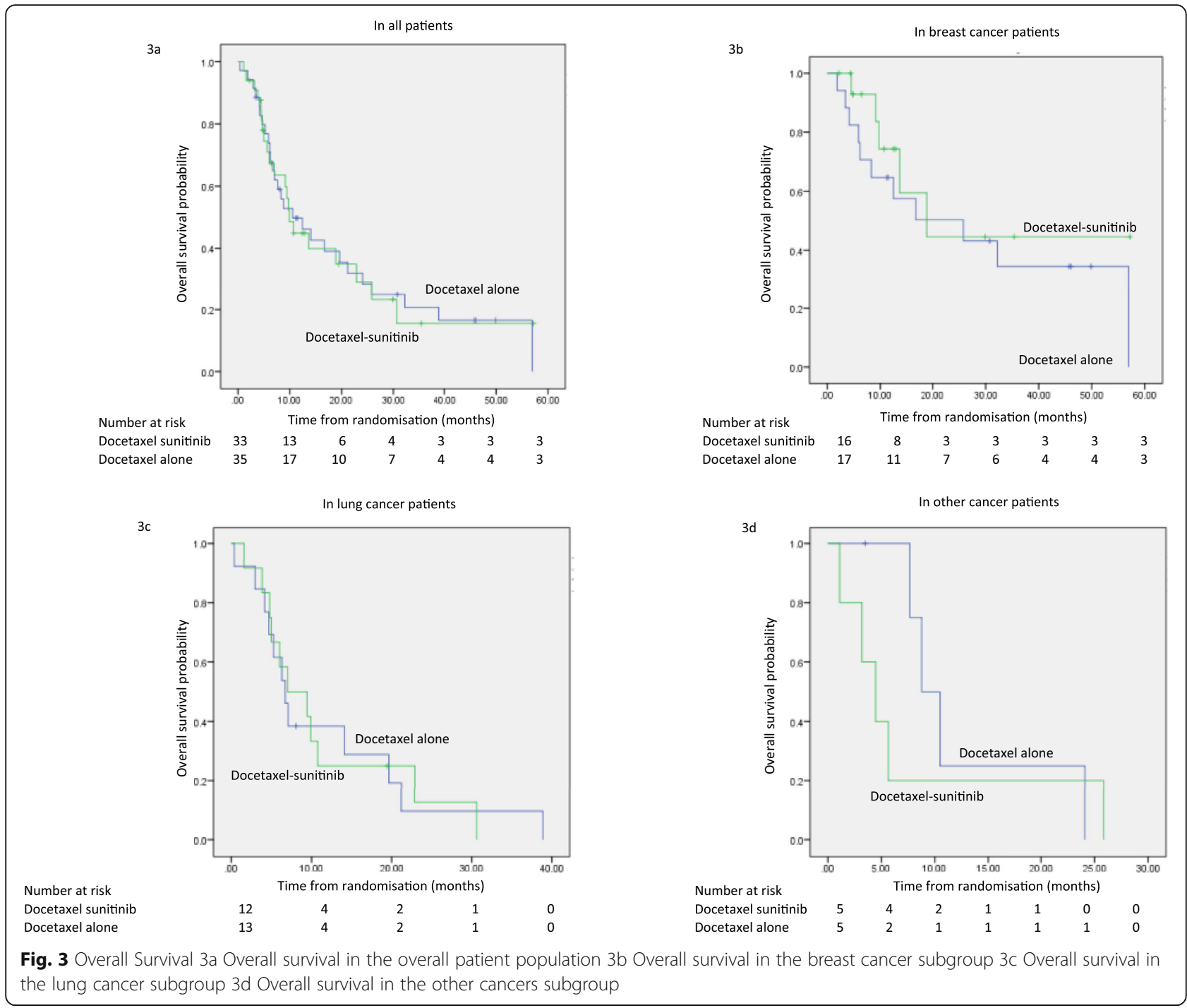

sunitinib may be insufficient to translate to a clinically significant difference. Another possible reason is that our current dose and schedule of sunitinib is not the clinically optimal regimen to normalize tumour vasculature in combination with docetaxel. In our previous neoadjuvant AC-sunitinib trial, we observed normalization of tumour vasculature to occur as early as $24 \mathrm{~h}$ after treatment, with the most significant increase in vascular normalization index occurring after the first cycle of chemotherapy, but only modest further increase with subsequent treatment cycles. This study and others underscore the sensitivity of tumour vasculature to dosing and scheduling of anti-angiogenic agents. In this current trial, we administered intermittent dosing sunitinib with up to 6 cycles of docetaxel, but did not observe any improvements in response rates compared to docetaxel alone. We hypothesize that while initial treatment with sunitinib does normalize tumour vasculature, repeated administration may conversely compromise normal tumour vasculature and eventually impair chemotherapy delivery. In fact, it may be possible that just a single cycle or two of sunitinib prior to starting chemotherapy may be sufficient to normalise tumour vasculature, but this is a question that will have to be addressed by a differently designed clinical trial. It is also uncertain as to whether the different mechanisms of action of AC (combining an intercalating and an alkylating agent) and docetaxel (which inhibits microtubule disassembly) act synergistically with sunitinib to varying extents, however, we do not expect this factor to have an impact on the results of our study. 
Table 2 Adverse Events

\begin{tabular}{|c|c|c|c|c|c|c|}
\hline \multirow[t]{2}{*}{ Toxicity } & \multicolumn{3}{|l|}{ All grades } & \multicolumn{3}{|l|}{ Grade 3 to 5} \\
\hline & $\begin{array}{l}\text { Docetaxel-sunitinib } \\
(N=33)\end{array}$ & $\begin{array}{l}\text { Docetaxel alone } \\
(N=35)\end{array}$ & $P$ value & $\begin{array}{l}\text { Docetaxel-sunitinib } \\
(N=33)\end{array}$ & $\begin{array}{l}\text { Docetaxel alone } \\
(N=35)\end{array}$ & $P$ value \\
\hline All toxicities & $84.8 \%$ & $91.4 \%$ & 0.400 & $30.3 \%$ & $42.9 \%$ & 0.285 \\
\hline Fatigue & $30.3 \%$ & $45.7 \%$ & 0.145 & $6.1 \%$ & $0 \%$ & 0.232 \\
\hline Peripheral neuropathy & $27.3 \%$ & $31.4 \%$ & 0.457 & $0 \%$ & $2.9 \%$ & 0.515 \\
\hline Diarrhoea & $27.3 \%$ & $25.7 \%$ & 0.551 & $0 \%$ & $0 \%$ & NA \\
\hline Neutropenia & $24.2 \%$ & $31.4 \%$ & 0.509 & $18.2 \%$ & $31.4 \%$ & 0.207 \\
\hline Nausea & $24.2 \%$ & $22.9 \%$ & 0.559 & $0 \%$ & $0 \%$ & NA \\
\hline Anorexia & $18.2 \%$ & $20.0 \%$ & 0.547 & $0 \%$ & $0 \%$ & NA \\
\hline Vomiting & $12.1 \%$ & $14.3 \%$ & 0.539 & $0 \%$ & $0 \%$ & NA \\
\hline Fever & $12.1 \%$ & $11.4 \%$ & 0.611 & $6.1 \%$ & $11.4 \%$ & 0.435 \\
\hline Cough & $12.1 \%$ & $8.6 \%$ & 0.466 & $0 \%$ & $0 \%$ & NA \\
\hline Xerostomia & $12.1 \%$ & $2.9 \%$ & 0.160 & $0 \%$ & $0 \%$ & NA \\
\hline Dizziness & $12.1 \%$ & $0 \%$ & 0.050 & $0 \%$ & $0 \%$ & NA \\
\hline Myalgia & $9.1 \%$ & $22.9 \%$ & 0.112 & $0 \%$ & $0 \%$ & NA \\
\hline Dyspnoea & $6.1 \%$ & $17.1 \%$ & 0.149 & $0 \%$ & $2.9 \%$ & 0.515 \\
\hline Dyspepsia & $6.1 \%$ & $14.3 \%$ & 0.239 & $0 \%$ & $0 \%$ & NA \\
\hline Mouth ulcers & $6.1 \%$ & $11.4 \%$ & 0.365 & $0 \%$ & $0 \%$ & NA \\
\hline Insomnia & $6.1 \%$ & $8.6 \%$ & 0.528 & $0 \%$ & $0 \%$ & NA \\
\hline Hypersensitivity & $6.1 \%$ & $5.7 \%$ & 0.670 & $0 \%$ & $0 \%$ & NA \\
\hline Herpes Zoster & $6.1 \%$ & $2.9 \%$ & 0.478 & $3.0 \%$ & $0 \%$ & 0.485 \\
\hline Sore throat & $6.1 \%$ & $2.9 \%$ & 0.478 & $0 \%$ & $0 \%$ & NA \\
\hline Dysgeusia & $3.0 \%$ & $5.7 \%$ & 0.522 & $0 \%$ & $0 \%$ & NA \\
\hline Lower limb oedema & $3.0 \%$ & $5.7 \%$ & 0.522 & $0 \%$ & $2.9 \%$ & 0.515 \\
\hline
\end{tabular}

Surprisingly, progression-free survival was actually significantly lower in patients who received sunitinib for the entire cohort. While this was a secondary endpoint of the trial and clear conclusions on survival cannot really be drawn, this result was nonetheless unexpected. The observed difference in PFS is unlikely to be due to differences in patient characteristics, which were well matched down to the number of previous lines of therapy, and primary tumour type. It is also not likely to be attributable to differences in toxicities, as toxicity rates were similar in both arms. There were more dose delays in patients on the docetaxel-sunitinib arm, despite the fact that there was a higher rate of growth factors administered in this arm; however, dose intensity of docetaxel administration was similar in both arms and again unlikely to account for the inferior PFS seen in those patients.

Interestingly, a Phase II trial that studied the addition of sunitinib $37.5 \mathrm{mg}$ daily to pemetrexed versus pemetrexed alone in the second line treatment of NSCLC has similarly shown detrimental effects on overall survival, although progression-free survival was not significantly different [18]. Multiple Phase III trials have added sunitinib or sorafenib to first-line chemotherapy in breast,

Table 3 Docetaxel Pharmacokinetics $(n=63)$

\begin{tabular}{llll}
\hline & Docetaxel-sunitinib & Docetaxel alone & $P$ value \\
\hline $\operatorname{Tmax}(\mathrm{h})$ & $0.95 \pm 0.43$ & $0.76 \pm 0.33$ & 0.060 \\
Cmax $(\mu \mathrm{g} / \mathrm{ml})$ & $4.28 \pm 2.07$ & $3.40 \pm 1.26$ & 0.044 \\
AUC $_{0-\infty}($ hours & $\mu \mathrm{g} / \mathrm{ml})$ & $4.85 \pm 1.76$ & 0.053 \\
Cl_pred $(\mathrm{L} / \mathrm{h})$ & $6.48 \pm 4.43$ & $27.4 \pm 8.7$ & 0.290 \\
Vss_pred (L) & $24.4 \pm 13.2$ & $198.5 \pm 148.6$ & 0.922 \\
\hline
\end{tabular}

Tmax time to peak serum concentration; Cmax maximum serum concentration; AUCO- $\infty$ area under concentration-time curve; Cl_pred predicted clearance; Vss_pred predicted volume of distribution at steady state 
lung and colorectal cancers, all of which did not result in poorer PFS [3-5]. One potential reason is that these trials, as well as our prior neoadjuvant AC-sunitinib trial, evaluated relatively treatment-naïve patients receiving first line systemic therapy, whereas patients in our current trial and the negative Phase II lung cancer trial were more heavily pre-treated, suggesting that tumours that have had prior exposure to systemic therapies may be more resistant to the vasculature normalization effect of low dose sunitinib.

We noted on subgroup analysis that while PFS was significantly worse with the addition of sunitinib in breast and other cancers, this was not the case with the lung cancer subgroup. This observation is concordant with reported Phase III trials in non-squamous nonsmall cell lung cancers, where the addition of bevacizumab to carboplatin-paclitaxel, or the addition of ramucirumab or nintedanib to docetaxel, all showed survival benefits, in contrast to breast cancer studies on addition of bevacizumab to chemotherapy [2, 19-22]. This could potentially be due to differences in tumour vasculature and expression or influence of angiogenic growth factors in the different tumour types, in turn affecting response to anti-VEGF agents. In future studies, collection of tumour tissue for analysis of angiogenic growth factors such as VEGF receptors or Hypoxia Inducible Factor 1 Alpha (HIF1 Alpha) could help to shed light on this issue.

We observed that docetaxel AUC is higher in patients who received docetaxel with sunitinib than those who received docetaxel alone. Both docetaxel and sunitinib undergo hepatic metabolism by the cytochrome $\mathrm{P} 450$ CYP3A4 system, and we postulate that the concomitant administration of both drugs may slow docetaxel metabolism and excretion, leading to a higher docetaxel AUC. Yet despite this higher docetaxel AUC, we do not see corresponding improvements in response rate or increases in toxicity. PFS and response rates also did not correlate with docetaxel AUC.

Our study has several limitations. The sample size was small, patients were recruited from only two institutions, and treatment was not blinded. In addition, the study recruited patients with a variety of solid tumors rather than focused on a single tumor type. Although we had initially hypothesized that different solid tumors will have broadly similar response to the therapeutic strategy of low-dose, short-course sunitinib to improve chemotherapy delivery and efficacy, we did stratify patients by tumor type before randomization and found preliminary evidence from this study that there is indeed heterogeneity in responses between different tumor types. Finally, overall survival follow-up is immature for breast cancer patients in our trial, with 6 of 33 patients still alive at data-cutoff of 5 years.

\section{Conclusions}

In conclusion, the addition of low-dose, short-course sunitinib to docetaxel chemotherapy is well tolerated, but did not improve objective response or clinical benefit rates in advanced solid tumours. These negative results suggest that the intermittent administration of sunitinib in the current dose and schedule with docetaxel in advanced solid tumours, particularly breast cancers, is not beneficial. If this strategy were to be explored further, then additional studies will be warranted to determine the optimal regimen of anti-angiogenic agents in combination with chemotherapy to achieve improved drug delivery, to ascertain if pathologic tumour vasculature changes can translate into meaningful clinical benefit, and to identify groups of patients most likely to benefit from this strategy.

\section{Acknowledgements}

We would like to thank all the patients who participated in this study.

\section{Authors' contributions}

The principal investigator, $\mathrm{SCL}$, was responsible for the trial design and development of the protocol. GFH, RAS, RS, SHT, WPY, SGWO, JSJL, WQC and $B C G$ recruited patients to the study and performed study related procedures. LW was responsible for performing pharmacokinetic analyses, and BCT for the statistical design of the study. Data collection and analysis were done by YA and PPS. The decision to publish the trial data and final decisions with regard to the content of the manuscript were made by the principal investigator in consultation with all co-authors. All authors had access to the primary data and take responsibility for the veracity and completeness of the data reported. All authors approved the final version of the manuscript.

\section{Funding \\ This study was funded by the National Medical Research Council RIE2015 National Cancer Institute of Singapore Centre Grant (NMRC/CG/012/2013), the National Medical Research Council RIE2020 National Cancer Institute of Singapore Centre Grant (NMRC/CG/M005/2017_NCIS) and the National Medical Research Council Clinician Scientist Award- Senior Investigator Category (NMRC/CSA-SI/0004/2015). The funders had no role in study design, data collection and analysis, decision to publish, or preparation of the manuscript.}

\section{Availability of data and materials}

The datasets generated during and/or analysed during the current study are available from the corresponding author on reasonable request.

\section{Ethics approval and consent to participate}

The study was approved by the institutional review board at each participating centre (Domain Specific Research Board approved on 23rd April 2013 for the Singapore site [Reference number 2013/00170] and Medical Ethics Committee University Malaya Medical Centre on 19th June 2013 for the Malaysia site [Protocol number BR01/08/13]) and was conducted in accordance with the Declaration of Helsinki and Good Clinical Practice guidelines.

Written informed consent was obtained from all individual participants included in the study.

\section{Consent for publication}

Not applicable.

\section{Competing interests}

RAS: Honoraria: Astra Zeneca, BMS, Boehringer Ingelheim, Eli-Lilly, Merck, Novartis, Pfizer, Roche and Taiho; Research grant: Astra-Zeneca.

RS: Advisory board: BMS, Merck, Eisai, Bayer, Taiho; honoraria for talks: MSD, Eli Lilly, BMS, Roche, Taiho; Travel funding: Roche, Astra Zeneca, Taiho, Eisai; Research funding: Paxman Coolers, MSD. 
These are outside the submitted work.

SGWO: Honoraria: Pfizer, Astra Zeneca, Novartis, Eli Lily.

BCT: Honoraria for workshops: Boehringer Ingelheim; Royalty: Wiley-Blackwell. SCL: Advisory board: Roche, MSD, Astra Zeneca, Pfizer, Novartis, Eli Lilly, ACT Genomics, Eisai; honoraria for talks: Astra Zeneca, Pfizer, Novartis, ACT Genomics, Eisai; Research Funding: Taiho, Eisai, Pfizer, ACT Genomics, ASLAN Pharmaceuticals Ltd.; Travel funding for conferences: Amgen, Pfizer. The other authors declare that they have no competing interests.

\section{Author details}

'Department of Haematology-Oncology, National University Cancer Institute, National University Health System, Level 7, NUHS Tower Block, 1E Kent Ridge Road, Singapore 119228, Singapore. ${ }^{2}$ University of Malaya Medical Centre, Kuala Lumpur, Malaysia. ${ }^{3}$ Cancer Science Institute, National University of Singapore, Singapore, Singapore. ${ }^{4}$ The N.1 Institute for Health, National University of Singapore, Singapore, Singapore. ${ }^{5}$ Yong Loo Lin School of Medicine, National University of Singapore, Singapore, Singapore. ${ }^{6}$ OncoCare Cancer Centre, Singapore, Singapore. ${ }^{7}$ Saw Swee Hock School of Public Health, National University of Singapore, Singapore, Singapore.

Received: 29 July 2020 Accepted: 4 November 2020

Published online: 17 November 2020

\section{References}

1. Hurwitz H, Fehrenbacher L, Novotny W, Cartwright T, Hainsworth J, Heim W, et al. Bevacizumab plus irinotecan, fluorouracil, and leucovorin for metastatic colorectal cancer. N Engl J Med. 2004;350:2335-42.

2. Sandler A, Gray R, Perry MC, Brahmer J, Schiller JH, Dowlati A, et al. Paclitaxel-carboplatin alone or with bevacizumab for non-small-cell lung cancer. N Engl J Med. 2006:355:2542-50.

3. Carrato A, Swieboda-Sadlej A, Staszewska-Skurczynska M, Lim R, Roman L, Shparyk Y, et al. Fluorouracil, leucovorin, and irinotecan plus either sunitinib or placebo in metastatic colorectal cancer: a randomized, phase III trial. J Clin Oncol. 2013;31(10):1341-7.

4. Bergh J, Bondarenko IM, Lichinitser MR, Liljegren A, Greil R, Voytko NL, et al. First-line treatment of advanced breast cancer with sunitinib in combination with docetaxel versus docetaxel alone: results of a prospective, randomized phase III study. J Clin Oncol. 2012;30(9):921-9.

5. Paz-Ares LG, Biesma B, Heigener D, von Pawel J, Eisen T, Bennouna J, et al. Phase III, randomized, double-blind, placebo-controlled trial of gemcitabine/ cisplatin alone or with sorafenib for the first-line treatment of advanced, nonsquamous non-small-cell lung cancer. J Clin Oncol. 2012;30(25):3084-92.

6. Duda DG, Batchelor TT, Willett CG, Jain RK. VEGF-targeted cancer therapy strategies: current progress, hurdles and future prospects. Trends Mol Med. 2007;13(6):223-30.

7. Willett CG, Boucher Y, di Tomaso R, Duda DG, Munn LL, Tong RT, et al. Direct evidence that the VEGF-specific antibody bevacizumab has antivascular effects in human rectal cancer. Nat Med. 2004;10(2):145-7.

8. Gradishar WJ, Kaklamani V, Sahoo TP, Lokanatha D, Raina V, Bondarde S, et al. A double-blind, randomised, placebo-controlled, phase $2 \mathrm{~b}$ study evaluating sorafenib in combination with paclitaxel as a first-line therapy in patients with HER2-negative advanced breast cancer. Eur J Cancer. 2013; 49(2):312-22.

9. Baselga J, Roche H, Costa F, Getulio Martins Segalla J, Pinczowski H, Ma Ciruelos E, et al. SOLTI-0701: A multinational double-blind, randomized Phase $2 \mathrm{~b}$ study evaluating the efficacy and safety of sorafenib compared to placebo when administered in combination with capecitabine in patients with locally advanced or metastatic breast cancer (BC). Cancer Res. 2009; 69(24 Suppl):Abstract $\mathrm{nr} 45$.

10. Winkler F, Kozin SV, Tong RT, Chae SS, Booth MF, Garkavtsev I, et al. Kinetics of vascular normalization by VEGFR2 blockage governs brain tumor response to radiation: role of oxygenation, angiopoietin-1, and matrix metalloproteases. Cancer Cell. 2004;6(6):553-63.

11. Jain RK. Normalization of tumor vasculature: an emerging concept in antiangiogenic therapy. Science. 2005;307(5706):58-62.

12. Wong ALA, Sundar R, Wang T-T, Ng T-C, Zhang B, Tan S-H, et al. Phase Ib/II randomized, open-label study of doxorubicin and cyclophosphamide with or without low-dose, short-course sunitinib in the pre-operative treatment of breast cancer. Oncotarget. 2016;7(39):64089-99.
13. Schulz KF, Altman DG, Moher D. CONSORT 2010 Statement: updated guidelines for reporting parallel group randomised trials. BMC Med. 2010;8: 18.

14. Eisenhauer EA, Therasse P, Bogaerts J, Schwartz LH, Sargent D, Ford R, et al. New response evaluation criteria in solid tumours: revised RECIST guideline (version 1.1). Eur J Cancer. 2009;45:228-47.

15. Goh BC, Lee SC, Wang LZ, Fan L, Guo JY, Lamba J, et al. Explaining interindividual variability of docetaxel pharmacokinetics and pharmacodynamics in Asians through phenotyping and genotyping strategies. J Clin Oncol. 2002;20(17):3683-90.

16. Nabholtz JM, Senn HJ, Bezwoda WR, Melnychuk D, Deschenes L, Douma J, et al. Prospective randomized trial of docetaxel versus mitomycin plus vinblastine in patients with metastatic breast cancer progressing despite previous anthracycline-containing chemotherapy. 304 study group. J Clin Oncol. 1999;17(5):1413-24.

17. Fossella FV, DeVore R, Kerr RN, Crawford J, Natale RR, Dunphy F, et al. Randomized phase III trial of docetaxel versus vinorelbine or ifosfamide in patients with advanced non-small-cell lung cancer previously treated with platinum-containing chemotherapy regimens. The TAX 320 non-small cell lung Cancer study group. J Clin Oncol. 2000;18(12):2354-62.

18. Heist RS, Wang X, Hodgson L, Otterson GA, Stinchcombe TE, Gandhi L, et al. CALGB 30704 (Alliance): a randomized phase II study to assess the efficacy of pemetrexed or sunitinib or pemetrexed plus sunitinib in the second-line treatment of advanced non small-cell lung cancer. J Thorac Oncol. 2014; $9(2): 214-21$

19. Reck M, Kaiser R, Mellemgaard A, Douillard J-Y, Orlov S, Krzakowski M, et al. Docetaxel plus nintedanib versus docetaxel plus placebo in patients with previously treated non-small-cell lung cancer (LUME-lung 1): a phase 3, double-blind, randomised controlled trial. Lancet Oncol. 2014;15(2):143-55.

20. Garon EB, Ciuleani T-E, Arrieta O, Prabhash K, Syrigos KN, Goksel T, et al. Ramucirumab plus docetaxel versus placebo plus docetaxel for second-line treatment of stage IV non-small-cell lung cancer after disease progression on platinum based therapy (REVEL): a multicenter, double-blind, randomised phase 3 trial. Lancet. 2014;384(9944):665-73.

21. Miller K, Wang M, Gralow J, Dickler M, Cobleigh M, Perez EA, et al. Paclitaxel plus bevacizumab versus paclitaxel alone for metastatic breast cancer. $\mathrm{N}$ Engl J Med. 2007;357:2666-76.

22. Robert NJ, Dieras V, Glaspy J, Brufsky AM, Bondarenko I, Lipatov ON, et al. RIBBON-1: randomized, double-blind, placebo-controlled, phase III trial of chemotherapy with or without bevacizumab for first-line treatment of human epidermal growth factor receptor 2-negative, locally recurrent or metastatic breast cancer. J Clin Oncol. 2011;29(10):1252-60.

\section{Publisher's Note}

Springer Nature remains neutral with regard to jurisdictional claims in published maps and institutional affiliations.

Ready to submit your research? Choose BMC and benefit from:

- fast, convenient online submission

- thorough peer review by experienced researchers in your field

- rapid publication on acceptance

- support for research data, including large and complex data types

- gold Open Access which fosters wider collaboration and increased citations

- maximum visibility for your research: over $100 \mathrm{M}$ website views per year

At BMC, research is always in progress.

Learn more biomedcentral.com/submissions 